\title{
PIBID E RESIDÊNCIA PEDAGÓGICA: PENSANDO A FORMAÇÃo DE PROFESSORES DE LÍNGUAS POR MEIO DOS SUBPROJETOS DE INGLÊS
}

Pibid and Pedagogical Residency Program: Thinking the Language Teacher Education through the analysis of the English Subprojects

\author{
Ana Karina de Oliveira NASCIMENTO (UFS) ${ }^{1}$ \\ Maria Amália Vargas FAÇANHA (UFS) ${ }^{2}$ \\ Marlene de Almeida Augusto de SOUZA (UFS) ${ }^{3}$
}

\begin{abstract}
RESUMO: A maioria dos cursos de formação de professores concentra as horas de estágio supervisionado nos semestres finais da graduação. É nesse momento que os professores em formação construirão, de forma sistematizada, o conhecimento sobre ensinar e aprender uma língua a partir da relação que estabelecerão entre seus conhecimentos prévios e as trocas com o professor de estágio supervisionado, o professor da escola parceira, os alunos, e todos os elementos do contexto escolar. Em 2018, a CAPES lançou dois editais de projetos voltados para a formação de professores: Programa Institucional de Bolsa de Iniciação à Docência (Pibid) e Programa de Residência Pedagógica (RP). Com o objetivo de entender como as propostas dos editais foram materializadas na Universidade Federal de Sergipe e como estas influenciam na formação de professores de línguas para a educação básica, especialmente, de inglês, neste artigo são discutidos os seguintes aspectos: a concepção de formação de professor; o papel do coordenador de área, do professor supervisor e do professor em formação; e as influências das propostas do Pibid e do RP na formação de professores de línguas. Análises preliminares apontam para uma ampliação dos processos de formação em virtude das possibilidades abertas pelos dois programas.
\end{abstract}

PALAVRAS-CHAVE: formação de professores; Pibid; Residência Pedagógica; inglês.

\begin{abstract}
Most pre-service teacher education programs concentrate the hours of practicum in the last semesters of the undergraduate program. It is at that moment that pre-service teachers will build, in a systematized way, the knowledge about teaching and learning a language based on the relationship they will establish among their previous knowledge and the exchanges with the teacher of practicum, the teacher of the participant school, the students, and all elements of the school context. In 2018, CAPES launched two calls for projects
\end{abstract}

\footnotetext{
${ }^{1}$ Professora na Universidade Federal de Sergipe (UFS). Doutora em Letras pela Universidade de São Paulo (USP) no Programa de Pós-Graduação em Estudos Linguísticos e Literários em Inglês. akcoliveira@gmail.com

${ }^{2}$ Professora na Universidade Federal de Sergipe (UFS). Doutora em Educação pela Universidade Federal de Sergipe (UFS), na Linha Educação, Comunicação e Diversidade. amaliafvargas@ gmail.com

${ }^{3}$ Professora na Universidade Federal de Sergipe (UFS). Doutora em Letras pela Universidade de São Paulo (USP) no Programa de Pós-Graduação em Estudos Linguísticos e Literários em Inglês. marlenesouza04@yahoo.com.br
} 
aimed at teacher education: National Pre-service Brazilian Teacher Education Program (Pibid) and Pedagogical Residency Program (RP). In order to understand how CAPES proposals were materialized at the Federal University of Sergipe and how they can influence on language teacher education programs, especially English teacher education, this article discusses the following aspects: the conception of teacher education; the role of the area coordinator, teacher supervisor and pre-service teacher; and the influences of Pibid and RP proposals on the education of language teachers. Preliminary analysis point to an expansion of teacher education processes due to the possibilities opened by the two programs.

KEYWORDS: teacher education; Pibid; Pedagogical Residency Program; English.

\section{INTRODUÇÃO}

A Resolução 02/15 CNE-MEC, que apresenta as diretrizes curriculares nacionais para a formação inicial e continuada dos profissionais do magistério, orienta que o projeto de formação inicial e continuada de professores deve ser elaborado e desenvolvido a partir da articulação entre a instituição de ensino superior (IES) e a educação básica (EB).

Em 2018, a Coordenação de Aperfeiçoamento de Pessoal de Nível Superior (CAPES) lançou dois editais de projetos voltados para a formação de professores: edital CAPES n $n^{\text {o. }}$ 06/2018 com chamada pública para apresentação de propostas no âmbito do Programa de Residência Pedagógica (RP), para os alunos que tinham cumprido $50 \%$ do curso de licenciatura ou que estivessem cursando a partir do $5^{\circ}$ semestre; e edital CAPES $n^{\text {o. }}$ 07/2018 com chamada pública para apresentação de propostas no âmbito do Programa Institucional de Bolsa de Iniciação à Docência (Pibid), para os alunos que estivessem na primeira metade do curso.

Ambos os programas podem contribuir significativamente na formação inicial dos alunos, já que ampliam os espaços de formação teórico-prático. Além disso, contribuem na formação continuada dos professores atuantes na EB da rede pública, que poderão participar dos projetos como preceptores no RP ou como supervisores no Pibid. Ou seja, esses programas permitem a articulação entre as IES e a EB prevista na Resolução 02/15 CNE-MEC, constituindo-se em novos espaços para que os professores formadores criem condições para que os professores em formação (continuada) encontrem diferentes formas de construir conhecimentos (MENEZES DE SOUZA, 2011a). 
REVISTA X, Curitiba, volume 14, n.5,p. 106-125, 2019

Este artigo tem por objetivo entender como as propostas dos editais foram pensadas e desenvolvidas na Universidade Federal de Sergipe (UFS) e como estas influenciam a formação de professores de línguas para a EB a partir das perspectivas da Coordenadora Institucional (CI) do Pibid da UFS, de uma das Coordenadoras de Área (CA) do Pibid e de uma das CA do RP, ambas do curso de Letras Inglês. Trata-se de um texto resultante de pesquisa documental, bem como de relatos de experiências vividas pelas autoras.

\section{IMPLEMENTAÇÃO DO PIBID E RP NA UFS}

Na UFS, foram aprovados os projetos institucionais de ambos os programas: Pibid e RP. Tanto no caso do Pibid quanto no do RP, há dois subprojetos especificamente de Língua Inglesa, totalizando quatro núcleos formados por quatro coordenadores de área (CA), seis preceptores do RP e seis supervisores do Pibid, quarenta e oito residentes, quarenta e oito bolsistas de iniciação à docência (ID) e doze voluntários de ID, ou seja, ambos os projetos totalizam cento e doze participantes da UFS e doze da EB (vide tabela 1). Tais projetos estão sendo desenvolvidos em 11 (6 do Pibid e 5 do RP) escolas públicas localizadas na capital e grande Aracaju.

\begin{tabular}{|l|l|l|}
\hline \multirow{4}{*}{ LÍNGUA INGLESA } & \multicolumn{1}{|c|}{ PIBID } & \multicolumn{1}{c|}{ RP } \\
\cline { 2 - 3 } & 2 coordenadores & 2 coordenadores \\
\cline { 2 - 3 } & 6 supervisores & 6 preceptores \\
\cline { 2 - 3 } & 48 bolsistas & 48 bolsistas \\
\cline { 2 - 3 } & 12 alunos voluntários 12 alunos voluntários \\
\cline { 2 - 3 } & \multicolumn{2}{|c|}{112 participantes } \\
\cline { 2 - 3 } & 6 escolas & 5 escolas \\
\hline
\end{tabular}

Tabela 1: Pibid e RP na UFS em números

No curso de licenciatura de Língua Inglesa os alunos começam a ter contato com as aulas na EB, de forma sistematizada, a partir do $5^{\circ}$ semestre. Sendo assim, apenas depois de dois anos no curso na licenciatura, os professores em formação têm a oportunidade de observar/reger aulas na EB e discutir, a partir dos mais diferentes conceitos teóricos, o processo de ensino e aprendizagem com o professor de estágio e seus colegas. 
A participação dos alunos nos projetos Pibid e RP, então, mostra-se uma oportunidade para que os alunos tenham experiências nas salas de aula da EB em escolas públicas durante todo o curso, contribuindo significativamente em sua formação profissional. No caso do Pibid-UFS, os alunos que participam do projeto têm a oportunidade de observar, participar e analisar a realidade das aulas de inglês na EB desde sua entrada na licenciatura, totalizando de dois anos a dois anos e meio de observação. E, no caso do RP, os alunos antecipam em um ano a experiência com regência, podendo ampliá-la até o final do curso, ou seja, ao invés de um ano de regência previsto na matriz curricular dos cursos, eles poderão ter entre dois anos e dois anos e meio.

Nesse sentido, os programas propostos pelo governo federal podem complementar a formação que os cursos de licenciatura já vêm oferecendo. A implementação requer uma análise dos editais para se identificar o que se entende por formação de professor de modo a identificar as limitações que tais propostas podem impor às necessidades e realidades locais. Ou seja, é preciso construir um “conhecimento local” que é, para Canagarajah (tradução nossa), “[...] um processo de negociação dos discursos dominantes e envolvimento em uma construção contínua de conhecimento relevante no contexto de nossa história e prática " ${ }^{4}$ (CANAGARAJAH, 2002, p. 251). No caso dos programas Pibid e RP da UFS, ambos exigiram um processo de desconstrução do conhecimento/proposta de um grupo dominante buscando entender as características locais, e um processo de reconstrução do conhecimento do local de modo a atender as necessidades contemporâneas (CANAGARAJAH, 2002).

Dentre as orientações apresentadas no edital da CAPES para a elaboração dos subprojetos do Pibid e do RP, neste artigo, analisaremos especificamente quatro pontos apresentando as possíveis consequências na elaboração dos projetos, bem como nos encaminhamentos das propostas na formação dos professores: (1) perfil de coordenadores de área e supervisores e preceptores que poderiam participar; (2) seleção das escolas participantes dos subprojetos; (3) elaboração dos subprojetos; (4) quantidade de participantes em cada núcleo.

Tais pontos serão analisados considerando a afirmação de Kumaradivelu (2014), de que não apenas os planos curriculares, design de materiais, métodos de ensino, testes

\footnotetext{
4 “[...] a process of negotiating dominant discourses and engaging in an ongoing construction of relevant knowledge in the context of our history and social practice.” (CANAGARAJAH, 2002, p. 251).
} 
padronizados, como também as propostas de formação de professores são forças hegemônicas, por definirem previamente os caminhos a serem seguidos independentemente das características e necessidades locais.

Com relação ao primeiro ponto, que trata do perfil de coordenadores de área e supervisores e preceptores, o edital determinava que os professores interessados em participar dos projetos deveriam preencher o currículo na Plataforma Freire de forma que atendessem minimamente aos critérios pré-estabelecidos em termos de formação e de experiências.

Em relação à formação e experiência profissional, os itens 6.3 e 6.4 dos Editais $n^{\circ}$ 06/2018 e 07/2018 estabelecem, respectivamente,quatro requisitos mínimos para os coordenadores de área, e três requisitos mínimos para os supervisores e preceptores. Dentre tais exigências, destacamos uma que afetou o processo de seleção tanto de coordenadores de área quanto de supervisores: a exigência quanto a possuir licenciatura na área específica do subprojeto a que a pessoa se candidataria.

No caso dos coordenadores de área, que são os professores da universidade, não é raro que eles tenham graduação em área diferente da que esteja atuando, já que os concursos normalmente exigem que mestrado e/ou doutorado seja de mesma área do curso a que a vaga é destinada. Por exemplo, no Pibid-UFS uma professora do curso de Pedagogia, graduada em Psicologia, com mestrado e doutorado na área de educação,não pode ser cadastrada na Plataforma Freire, já que sua licenciatura não era na área do subprojeto de Pedagogia. Fato semelhante aconteceu com os professores do curso de música que, em sua maioria, não têm a graduação-licenciatura em música, mas o mestrado/doutorado são nesta área. Como todas as informações eram inseridas e controladas pela Plataforma Freire, esses professores não puderam participar do projeto. No caso do curso de Música, não foi possível criar um núcleo, já que não havia nenhum professor que atendesse a esses requisitos mínimos, consequentemente os alunos de Música não puderam participar do Pibid. A exclusão deste subprojeto poderia ter sido evitada, caso as regras do edital pudessem ser adequadas de acordo com as características dos diferentes cursos, das diferentes universidades.

Situação semelhante aconteceu durante o cadastro de alguns supervisores e preceptores do Pibid e RP que não puderam ser incluídos no projeto por não terem licenciatura correspondente ao componente curricular ou ao curso do subprojeto, física, química, matemática, por exemplo. É importante registrar que esses professores atuam 
na rede pública de educação básica, mesmo que tenham apenas bacharelado. Ainda que entendamos e defendamos a necessária formação do professor em cursos de licenciatura, também visualizamos que os contextos locais são ignorados pela rigidez do edital e seus mecanismos. Além disso, permitir que esses professores sem uma formação específica participem do projeto poderia contribuir para que eles refletissem sobre suas práticas pedagógicas. No caso do RP, não houve problema semelhante, havendo um núcleo de música, uma vez que uma retificação no Edital CAPES $\mathrm{n}^{\circ}$ 06/2018 permitiu que o professor da educação básica (preceptor) possuísse licenciatura correspondente ao componente curricular ou ao curso do subprojeto. Na primeira versão do Edital, contudo, havia a seguinte exigência como requisito mínimo para o recebimento de bolsa de preceptor: "Ser licenciado na área/disciplina do residente que irá acompanhar" (BRASIL, 2018, p.06).

Tanto no caso de impedimento de inclusão de coordenadores de área quanto de supervisores e preceptores por não possuírem licenciatura na área específica do subprojeto, os editais do Pibid e RP, aqui considerado em uma perspectiva global, por definir os encaminhamentos para os projetos em todo o Brasil, apresentam um viés de homogeneização, não abrindo espaços para que cada lugar assimile as informações de acordo com sua própria realidade (SUÁREZ-OROZCO; QIN-HILLIARD, 2007).

No que diz respeito a outro ponto presente no edital da CAPES - seleção das escolas de EB para participação dos subprojetos do Pibid e do RP - vale destacar o fato de que os coordenadores deveriam escolher dentre as escolas previamente cadastradas na Plataforma Freire pela CAPES. O cadastro das escolas foi feito sem nenhuma consulta aos professores da universidade, das escolas de EB, nem mesmo às secretarias da educação. Além disso, a CAPES não enviou nenhum documento explicando os critérios para o cadastro de tais escolas. Normalmente, os órgãos governamentais consideram o índice do IDEB das escolas, incluindo, aquelas com o menor índice, em diferentes projetos na expectativa de se encontrar encaminhamentos que contribuam para a melhoria no aprendizado dos alunos. No entanto, este não foi o critério adotado pela CAPES para o cadastro das escolas a serem selecionadas pelos projetos do Pibid e RP, já que na lista constavam escolas classificadas como de excelência, que apresentam os melhores índices no IDEB no estado.

O terceiro ponto que constava no edital, elaboração dos subprojetos, também limitava as possibilidades de propostas dos coordenadores de modo que fossem 
adequadas aos contextos das escolas onde os projetos seriam implementados, por dois motivos. O primeiro motivo estava relacionado ao fato de que os subprojetos deveriam ser cadastrados na Plataforma Freire a partir da seleção de etapas e atividades já prédefinidas no sistema pela própria CAPES. Além disso, o cadastro dos subprojetos aconteceu antes da definição das escolas onde seriam desenvolvidos. Ou seja, os coordenadores de área não tinham informações sobre as características da escola e os interesses e necessidades dos professores e alunos, que ajudariam a definir não só os objetivos dos subprojetos, mas também as etapas e as atividades que atenderiam os diferentes contextos. Tais características nesta fase do processo de cadastro dos subprojetos na Plataforma Freire limitavam a atuação dos coordenadores de área, enquanto formadores de professores, a consumidores de propostas de formação de professores já pré-definidas por instâncias superiores, neste caso, a CAPES, dificultando sua atuação como produtores de conhecimentos e de propostas didáticos pedagógicas (KUMARADIVELU, 2014).

Outro ponto dos editais dos programas Pibid e RP que precisa ser analisado e problematizado diz respeito à quantidade obrigatória de orientandos, entre supervisores e preceptores, alunos de ID e residentes, por coordenador de área. Cada coordenador de área deveria ter 03 supervisores ou preceptores, 24 alunos bolsistas de iniciação à docência (ID) ou residentes e 06 alunos voluntários (não obrigatório, mas preferencialmente, conforme explicitado na tabela 2 .

\begin{tabular}{|l|l|}
\hline \multicolumn{2}{|c|}{ NÚCLEO } \\
\hline \multicolumn{2}{|c|}{ COORDENADOR } \\
\hline SUPERVISOR/PRECEPTOR 1 & 8 ALUNOS ID BOLSISTAS \\
& 2 ALUNOS ID VOLUNTÁRIOS \\
\hline SUPERVISOR/PRECEPTOR 2 & 8 ALUNOS ID BOLSISTAS \\
& 2 ALUNOS ID VOLUNTÁRIOS \\
\hline SUPERVISOR/PRECEPTOR 3 & 8 ALUNOS ID BOLSISTAS \\
& 2 ALUNOS ID VOLUNTÁRIOS \\
\hline \multicolumn{2}{|c|}{ TOTAL: de 27 a 33 orientandos } \\
\hline
\end{tabular}

Tabela 2: número de participantes por núcleo

Essa quantidade de orientandos por coordenador pode dificultar o acompanhamento mais frequente, com orientações específicas de todo o processo, desde a visita à escola, questões relacionadas especificamente às aulas, bem como sobre a análise de tais experiências de modo que não fiquem restritas a julgamentos negativos das práticas dos professores ("eles não têm domínio do conteúdo", "não sabem como 
lidar com o comportamento inadequado dos alunos", dentre outros). É importante que o professor formador (coordenador de área) tenha condições de criar espaços para que os professores em formação discutam e analisem as situações vivenciadas considerando os conceitos teóricos a partir dos aspectos do contexto que podem ajudar a explicar os eventos.

\section{PIBID E FORMAÇÃO DE PROFESSORES DEINGLÊSNA UFS}

Para o edital CAPES 07/2018 houve a oferta de 60 vagas para graduandos no subprojeto de inglês, sendo 48 para bolsistas e 12 para voluntários, a maior quantidade de bolsas para discentes da UFS no Pibid. Em 2011 eram 20 bolsas de iniciação à docência (doravante ID), ao passo que no edital de 2013 foram 45 bolsas. De maneira semelhante, há o aumento na oferta de bolsas para supervisores, professores da EB. No primeiro edital havia 3 supervisores, no segundo, 5, e neste último, 6 supervisores. Dessa forma estava clara a ampliação do programa, apesar de significar um grande desafio para cada coordenador de área orientar 30 ID e cada supervisor, 10. Ainda assim, resolvemos concorrer com uma proposta de Inglês.

Apesar do aumento significativo de participantes, sabe-se que o Pibid não atende localmente a todos os licenciandos da área de Inglês da UFS. Nem mesmo ao número de inscritos pleiteantes às vagas disponíveis em edital, tendo em vista a entrada anual na UFS de 100 discentes nos cursos de Letras Português-Inglês e Inglês (50 para cada um). Tal fato, conforme pontuado em outros trabalhos (ver NASCIMENTO, 2017), contribui para a existência de alguns licenciandos com possibilidades adicionais de formação, tendo em vista todo o trabalho realizado ao longo do Pibid. Outros, entretanto, não teriam as chances de formação em virtude da falta de oportunidades.

Um agravante à situação descrita é que em editais anteriores, a média geral ponderada dos licenciados era um item valorado. Com isso, adotava-se a lógica da meritocracia à formação inicial proporcionada pelo Pibid. Quanto a isto, é possível perceber que tinham mais chances aqueles com melhor desempenho acadêmico, ficando à margem do processo os licenciandos que possivelmente mais necessitavam de oportunidades de formação. Da maneira como estava posta, havia maior ênfase na linha de chegada até o momento da seleção, sem levar em conta os obstáculos enfrentados, inclusive os socioeconômicos. Assim, havia a tendência de selecionar os melhores 
alunos, que não necessariamente eram os que mais precisavam de um maior acompanhamento durante a formação, o que o Pibid pode oferecer.

Essa lógica anterior estava mais próxima às políticas e práticas neoliberais do que o que conseguimos consensuar em relação aos critérios de seleção para o edital de 2018. Naquele momento anterior, o individualismo e mérito e a consequente exclusão eram mais fortes do que atualmente, considerando que, no edital de 2018, o acréscimo de $10 \%$ na nota final em virtude de autodeclararão socioeconômica fez grande diferença na escolha de estudantes aos quais faltaram oportunidades anteriores de formação. $\mathrm{O}$ que entendemos por neoliberalismo refere-se a um conjunto de ideias que se caracterizam, dentre outros fatores, principalmente, pela individualidade, daí decorrendo a culpabilização do indivíduo pelo seu sucesso ou fracasso, além da adoção da lógica empresarial pelo indivíduo, fazendo parte da sua subjetividade, levando-nos a naturalizar a nossa existência e as relações que estabelecemos conforme a lógica empresarial: de que tudo é um produto a ser vendido, mensurado (NASCIMENTO, 2017; NASCIMENTO, 2018; DARDOT; LAVAL, 2013; PATRICK, 2013; STIEGLER, 2015). Destarte, o licenciando que não consegue fazer parte do Pibid é porque não estudou o suficiente (culpa individual), portanto, não possui méritos para ser contemplado com a bolsa. Nesse sentido, ter tido condições de discutir coletivamente as exigências do edital foi um grande passo dado institucionalmente para tornarmos menos individuais os critérios de seleção e contribuirmos para o fortalecimento de práticas mais democráticas de acesso à formação proporcionada pelo Pibid, a despeito da ainda atual exclusão proporcionada pelo programa nos cursos de graduação, ao contemplar uma minoria de licenciandos.

Esse processo de discussão institucional acerca de como funcionaria o programa - a seleção de graduandos - foi acompanhado por outras questões, a exemplo da escolha de professores formadores da nossa área que tivessem interesse de participar e atendessem às exigências do edital e cujo cadastro fosse aceito pela Plataforma Freire, mais uma plataforma de cadastro de currículo do professor. Isso porque o edital surge introduzindo novas exigências e atividades aos professores.

Duas professoras de língua inglesa do Departamento de Letras Estrangeiras, com pesquisa e atividades extensionistas ligadas à formação inicial e continuada de professores, assumiram a construção de uma proposta de subprojeto de inglês. Esta deveria acolher estudantes do início da graduação dos cursos de Letras Português-Inglês 
e Letras Inglês de forma a diminuir a distância que separa a universidade da EB. Isto porque, na UFS, os alunos dos cursos supracitados começam a ter contato, de forma sistematizada, com as aulas de inglês na EB das escolas públicas a partir do $5^{\circ}$ semestre, nas disciplinas voltadas para estágio de observação. Ou seja, apenas depois de dois anos e meio na graduação, os professores em formação têm a oportunidade de observar as aulas na EB e discutir, a partir dos mais diferentes conceitos teóricos, o processo de ensino e aprendizagem de línguas com o professor de estágio e seus colegas. A experiência na regência só vai acontecer um ano mais tarde, no $7^{\circ}$ semestre, às vésperas da conclusão do curso.

Além de promover o encurtamento da distância que separa o ensino superior e a formação de professores da EB, o programa também é uma forma de, por meio da concessão de bolsas (auxílio financeiro no valor de $\mathrm{R} \$ 400,00$ ), manter muitos dos bolsistas ID na universidade. Isto porque, no contexto local, há muitos licenciandos que, por questões financeiras desfavoráveis, acabam evadindo da graduação (NASCIMENTO, 2017). Nesse sentido, estavam claras as razões que nos levavam a optar por fazer parte do programa.

No tocante à seleção dos supervisores, conforme já pontuado na seção anterior, esta foi problemática tendo em vista a seleção prévia das escolas participantes ter sido feita pela CAPES, o que não apenas engessou nossas escolhas, mas também dificultou nosso trabalho no tocante ao subprojeto de Inglês tendo em vista o pequeno número de professores da área lotados nas escolas pré-selecionadas em razão da reduzida carga horária da disciplina na EB. Além do trabalho árduo de visitas às escolas selecionadas, deparamo-nos com informações que diferiam daquelas pesquisadas no site da secretaria de educação no tocante ao número de professores da área nas escolas; instituições localizadas em bairros de difícil acesso para os nossos licenciandos, muitos dos quais residentes no interior do estado, e, portanto, com dificuldades de locomoção; falta de interesse de professores em serem supervisores; não atendimento às exigências do edital CAPES por parte de muitos professores, especialmente quanto ao tempo mínimo de 2 anos de atuação na EB.

Ao discutir as questões aqui pontuadas e decidirmos de fato concorrer, e, após a proposta institucional ser aprovada pela CAPES, passamos à etapa seguinte que foi a elaboração do subprojeto de inglês. Naquele momento, enfrentamos dificuldades no tocante a, dentro de uma estrutura fechada, restrita à Plataforma Freire (havia caixas 
pré-definidas para preenchimento das informações, conforme discutido na seção anterior), materializarmos o subprojeto de inglês, de forma que pudéssemos problematizar questões relacionadas ao papel do ensino de inglês na EB, por meio de um processo segundo o qual todos nós (CA, supervisores e ID) pudéssemos ler o mundo lendo a nós mesmos. Ou seja, por meio do diálogo provocado pelas vivências pessoais, escolares e universitárias, tivéssemos a chance de vivenciar um processo que nos levasse a perceber que "haverá sempre um conflito de interpretações" (MENEZES DE SOUZA, 2011a, p. 297), já que "a linguagem é social e cultural, a linguagem nunca é abstrata, descontextualizada" [...] (Ibidem, p. 288).

O subprojeto de inglês do Pibid, então, contou com uma proposta circunscrita dentre 19 tipos de atividades pré-determinadas pela CAPES na Plataforma Freire. Contudo, havia, na Plataforma Freire, uma opção "Outra" que permitia a inserção de atividades além daquelas 19 pré-existentes. Então, neste espaço, incluímos: I) Participação em visitas às escolas; II) Levantamento das características locais, conhecimentos prévios e necessidades de professores e alunos das escolas participantes do projeto (pesquisa in loco, leitura de documentos escolares etc.); III) Implementação de projetos construídos coletivamente nas escolas participantes.

Optamos por colocar esses itens na opção "Outra" porque consideramos ser crucial para o desenvolvimento do Pibid registrar o trabalho de pesquisa atrelado à formação, seguindo o raciocínio de que as escolhas docentes devem ser informadas pelo contexto de atuação. Aqui nosso desejo era trabalhar no âmbito da responsabilidade ética do professor no mundo complexo atual, partindo da pergunta: "como é que nós vamos ensinar os nossos aprendizes a lidar com [as] diferenças sociais que permeiam [a] complexidade do mundo de hoje, sem levar os nossos aprendizes a quererem eliminar as pessoas que são diferentes, o que acaba gerando violência?" (MENEZES DE SOUZA, 2011a, p. 286).

Com esse intuito, iniciamos o Pibid-Inglês com visita inicial de todos do grupo às escolas participantes; posteriormente, após observações e vivências escolares, procedemos à elaboração de instrumentos diferentes para a construção de material empírico acerca das características locais e conhecimentos prévios de professores e alunos das escolas participantes do projeto (pesquisa in loco, leitura de documentos escolares etc). Essa etapa foi seguida de análise e discussão dos dados levantados. A partir das várias leituras feitas envolvendo ID, CA e supervisores, passamos a construir 
projetos que ajudassem os estudantes a (re)ler o mundo por meio da língua inglesa. Tínhamos o intuito de (re)pensar os porquês de muitas de suas atitudes na escola, especialmente questões que foram identificadas e que entendemos como formas de violência, as quais, muitas vezes eram ignoradas pelos professores, conforme identificadas pelos ID durante observações. Nesse sentido, passamos a planejar projetos, oficinas, participações nas aulas e atividades da escola, os quais encontram-se em fase de implementação.

As atividades realizadas no subprojeto de inglês têm buscado fomentar em bolsistas ID e supervisores reflexões críticas acerca do papel do professor e do ensino de inglês na educação básica (JORDÃO, 2013). Nesse sentido, as ações adotadas no subprojeto buscam considerar os aspectos sociais da língua, questionando as ideias de língua como algo neutro e composto por estrutura apenas, e problematizando-a como algo que é parte de um contexto social, cultural, histórico e ideológico. Nesse sentido, as atividades desenvolvidas têm buscado levar os alunos a (re)leituras de outras perspectivas além daquelas comumente atribuídas aos contextos pedagógicos, sociais, linguísticos.

Um exemplo dessas atividades foi a exibição de um documentário sobre educação no Brasil seguida de discussão no blog do subprojeto. Neste blog, diversificadas questões relacionadas à educação e mais especificamente ao ensino de inglês são objeto de discussão, a partir das provocações trazidas na forma de postagens pelas coordenadoras de área. A respeito desta postagem específica, cujo objetivo era refletir acerca do papel da educação pública, do que tem se realizado na educação básica e que conexões os graduandos conseguiam estabelecer com suas vivências escolares (na EB), houve várias interlocuções por parte dos ID e supervisores. Dentre estas, a postagem realizada por um dos bolsistas ID se mostrou significativa e por isso vai aqui em destaque, tendo em vista a sua relevância para a discussão realizada neste artigo:

Não sei para quantos discentes o efeito será o mesmo, mas eu chorei durante boa parte do documentário. Há tantas histórias ali, histórias que são como as nossas, de nossos conhecidos. Especialmente para mim, que venho de uma família onde tivemos de esperar muitas gerações para ter membros formados no Ensino Superior e que temos a cada dia mais, me é muito caro falar sobre experiências como as que foram relatadas no filme. Fui aluno de escola pública durante quase toda vida (sexto ano do fundamental até completar o ensino médio, sempre na mesma escola e vivenciando diariamente situações das mais díspares possíveis); moro em uma comunidade pobre, periférica, onde não se há a noção de importância da educação (sistêmico, não é culpa do povo); meus pais são separados e nunca tiveram a oportunidade de, de 
fato, poderem estudar, pois desde cedo tiveram de trabalhar para ajudar suas respectivas famílias. E, assim como eles, em dado momento, senti a obrigação de trabalhar (logo aos dezesseis) e desde então eu continuo trabalhando, porque não há, para pessoas como nós, outra opção senão a de se dedicar a algo que nos dê algum retorno financeiro para que não passemos dificuldade, porque a prioridade do pobre é colocar comida na mesa e sobreviver. Contudo, alguns professores me fizeram desde cedo apreciar a educação, que é para mim, simplesmente, uma das coisas mais valiosas da existência humana (como uma garota disse no documentário: "A única coisa que não podem nos tirar"). Não é fácil, como o documentário apresenta, deixar um garoto pobre e favelado sonhar, na verdade, há uma repressão (sistemática) a esses sonhos; uma determinação do que nós devemos ser, até onde podemos ir. E, a estrutura da sociedade, parece estar constituída para que isso aconteça, para que nossos sonhos sejam reprimidos. Alguns jovens (a cada dia mais) encontram professores que plantam a semente do sonhar, da possibilidade, do "e se". Não tenho certeza de como começou para mim, tenho mais de uma versão para quando preciso explicar, mas, para mim, sonhar sempre foi sobre ler (que não sei desde quando é maneira de fugir, atualmente nem tanto, e de compreender, ou ao menos tentar, a realidade). Talvez minhas palavras a seguir sejam os maiores clichês da vida (entre os maiores, com certeza), mas "professores são heróis" e "a educação é o melhor caminho de libertação" são minhas verdades platônicas. (FONTE: blog do subprojeto de Inglês do Pibid ${ }^{5}$ ).

O relato do bolsista ID trazido exemplifica como pensamos a condução do subprojeto de inglês do Pibid desde o princípio: como uma chance de nos permitir plantar cada vez mais a semente da possibilidade de ver, viver, interpretar e ressignificar o mundo por meio das leituras de nossas verdades e das verdades do outro.

\section{RP E FORMAÇÃO DE PROFESSORES DE INGLÊS NA UFS}

Diferente da trajetória já consolidada do Pibid na UFS e, em âmbito nacional, conforme descrito ao longo deste artigo, a história do Programa Residência Pedagógica começou a ser escrita recentemente. A chamada pública feita aos departamentos que hoje ofertam cursos de licenciatura na UFS aconteceu através do Edital $\mathrm{n}^{\circ}$ 10/2018/PROGRAD. Ao todo, 27 cursos da UFS estavam habilitados para participar do RP, dentre eles, os de Letras Português/Inglês e Letras Inglês.

A condição do número mínimo de 24 graduandos para abertura de núcleos apresentou-se como um desafio inicial do período de implementação do RP na UFS, assim como a seleção de preceptores que, assim como no Pibid, ficou limitada às escolas pré-selecionadas pela CAPES. O edital do RP foi divulgado internamente, através do site da instituição e do envio de e-mail departamental, para todos os discentes

\footnotetext{
${ }^{5}$ Disponível em: http://pibidinglesblog.blogspot.com/2018/10/roteiro-para-o-filme-nunca-me-sonharam. html. Acesso em: 01 nov. 2019.
} 
dos cursos de Letras Português/Inglês e Letras Inglês; e, externamente, a divulgação coube às secretarias de educação (municipal e estadual). Para nossa surpresa, considerando-se que se tratava de vagas remuneradas, verificou-se que o número de interessados (docentes e discentes), próximo ao encerramento do prazo estabelecido, não atingia o mínimo exigido para a abertura dos núcleos. Uma estratégia adotada pelas coordenadoras de área do RP (subprojeto Inglês), que inclui uma das autoras deste artigo, foi visitar as salas de aula dos cursos de Letras Português/Inglês (matutino) e Letras Inglês (noturno) da universidade e algumas escolas cadastradas e habilitadas a receberem o programa.

Percebemos, no contato com coordenadores/diretores/docentes de inglês das escolas, que não houve divulgação efetiva do programa por parte das secretarias de educação e das coordenações das escolas, o que ajudou a explicar o porquê das poucas inscrições recebidas. Com muito esforço, foram selecionados 06 docentes para atuarem como preceptores bolsistas em dois núcleos. Cabe destacar que nenhum deles havia tomado conhecimento do Edital através das escolas onde estão lotados. Quanto aos discentes, alguns elementos que ajudaram a explicar a baixa procura pelo programa foram: estar cursando o $5^{\circ}$ semestre da licenciatura ou já ter cursado $50 \%$ do curso, diferente do que acontece com o Pibid, que é voltado para os anos iniciais, em que as turmas são numerosas; a inserção no mercado de trabalho: alguns discentes já atuam, inclusive, como docentes de inglês em cursos de idiomas ou em estágios não obrigatórios; também casos de envolvimento em outros programas ou projetos de pesquisa e extensão da universidade, aí incluído o Pibid.

Apesar das dificuldades iniciais, conseguimos formar um núcleo na primeira fase de seleção. O segundo núcleo foi resultado de um novo edital aberto para o preenchimento de vagas ociosas. Assim, dois núcleos de inglês foram abertos, com 24 residentes cada, 06 voluntários, um para cada núcleo; 06 preceptores bolsistas e 01 preceptor voluntário. As atividades estão sendo desenvolvidas em 05 escolas. O preceptor voluntário não orienta residentes. Seu apoio tem sido através da participação em minicurso, como ministrante, o que será abordado mais adiante; e de participação nas discussões realizadas nos encontros que ocorrem na UFS com toda a equipe do RP de inglês.

Nos encontros na UFS, tratamos de questões pedagógicas e técnicas, com foco nos objetivos estabelecidos para o RP, os quais envolvem: o desenvolvimento de 
projetos que contribuam para fortalecer a relação entre teoria e prática, o que está em processo, com base no levantamento de dados para a construção de diagnóstico do campo da prática, questão estreitamente ligada ao papel do licenciando como pesquisador; a promoção do estreitamento e do fortalecimento dos laços entre universidade e escola pública; o desenvolvimento de ações que contribuam para a reformulação dos estágios supervisionados através da vivência dos atores envolvidos, tendo em vista a adequação das propostas pedagógicas dos cursos de formação inicial às orientações da Base Nacional Comum Curricular (BNCC).

Esse foco na BNCC apresenta-se como obrigatório para o RP, configurando-se como um grande desafio, não só para nossos residentes e preceptores, mas para todos os agentes envolvidos na área da educação, uma vez que o documento foi homologado em 20 de dezembro de 2017, e requer análise detalhada por parte de todos os envolvidos, na formação inicial e continuada. Assim como o RP, adequar a formação inicial e continuada à BNCC trata-se de um novo cenário que se desenha para a educação pública e que precisa ser muito discutido e analisado. Pensando nisso, e também atendendo a exigências do RP quanto à capacitação de docentes e discentes, ofertamos um minicurso de 12 horas, distribuídas em 03 encontros, aos sábados, nas dependências da UFS, como atividade de extensão.

O minicurso foi ministrado pelo docente preceptor voluntário, o qual coordenada o programa de implementação da BNCC localmente e é também um dos redatores do Currículo do Estado de Sergipe. Esse olhar de quem vem ajudando a desenhar o currículo local foi de extrema importância para todos os participantes. Nessa direção, a construção colaborativa de significados marcou os encontros. A ação teve os seguintes objetivos: apresentar o componente curricular Língua Inglesa na Base Nacional Comum Curricular e no Currículo de Sergipe; discutir sobre os desafios para a política de línguas estrangeiras a partir da implantação da BNCC e do Currículo; elaborar planos de aula alinhados à BNCC e ao Currículo com vistas a antecipar questões críticas da prática de ensino de Língua Inglesa. As reflexões que surgiram no minicurso buscaram enfatizar o valor dos saberes de todos os participantes.

Torna-se importante ressaltar que as discussões a respeito da BNCC, assim como todas as questões envolvidas nas atividades do RP, estão embasadas nas teorias dos letramentos (JORDÃO, 2016; JUCÁ, 2016), as quais entendem o fenômeno da linguagem/comunicação como prática construída na complexidade das relações sociais. 
Nossa proposta de análise do documento criado para reger as práticas educacionais em âmbito nacional buscou trazer para as discussões/reflexões a importância de sua interpretação, considerando-se as particularidades locais e as experiências de mundo de todos os participantes.

Nessa perspectiva, vimos buscando promover práticas de problematização constante e de (des)construção de narrativas, como a de que não se aprende língua estrangeira na escola pública e sobre o discurso de fracasso geral da escola. Na compreensão de que é necessário desafiar as generalizações, corroboramos o pensamento de Jesus e Lima, procurando sempre trazer para nossas práticas no RP questionamentos sobre "esses dizeres fixos da não aprendizagem que colaboram para a manutenção de um status quo que sustenta a destituição da escola pública como lugar possível de se aprender uma língua estrangeira" (JESUS; LIMA, 2016, p. 83).

Assim, reconhecendo todas as fragilidades e dificuldades pelas quais passa o ensino público, nossos esforços têm sido voltados para a importância do respeito às particularidades de cada local, de cada escola, de cada indivíduo, de cada comunidade. Nesse processo reflexivo, pensando nas práticas envolvendo a leitura de textos em língua inglesa, por exemplo, procuramos destacar o que Menezes de Souza (2011a, p. 296) defende como sendo uma prática necessária ao leitor atual, o exercício de "ler, se lendo", sob a perspectiva do letramento crítico. Ou seja, reconhecer as diferentes perspectivas a respeito das mais variadas formas de interpretação, na compreensão de que as leituras do outro são tão válidas quanto as minhas. Esse tem sido um exercício interessante e desafiador, uma vez que estão envolvidas, no RP, realidades de diferentes comunidades escolares, através das 04 escolas e dos 06 preceptores, cada um com suas trajetórias particulares.

Assim, considerando-se que vivemos tempos complexos, em que somos desafiados a lidar com diferentes formas de ler o mundo, as práticas desenvolvidas no RP visam ao respeito às diferentes formas de ensinar e de aprender. Nesse sentido, entendemos ser necessário problematizar a ideia de homogeneidade há muito aplicada à formação do cidadão e, por consequência, à educação. Assim, residentes e preceptores são incentivados a (re)pensar suas práticas docentes e discentes, buscando ampliar a compreensão entre heterogeneidade/homogeneidade na formação do indivíduo, o que se torna ainda mais pertinente com a homologação da BNCC. Somado a isso, está a consolidação da condição da língua inglesa como língua obrigatória nos currículos, a 
partir do $6^{\circ}$ ano do ensino fundamental, conforme a Lei de Diretrizes e Bases da Educação Nacional (LDB - lei 9.394/96), através da Lei 13.415, de 2017.

A ideia homogeneizante aplicada à formação do indivíduo ainda é bastante presente nas escolas brasileiras e, em particular, no ensino de línguas, o que vem sendo observado através da experiência no RP. Essa condição é fruto de um projeto de sociedade fundamentado, conforme destaca Monte Mór (2013), em conceitos como o de estado-nação, em que a harmonia entre língua, território e identidade foram disseminados como elementos essenciais. Entretanto, segundo a autora, essa coerência vem sendo constantemente desafiada pelos desdobramentos do projeto de globalização, acentuado pelos avanços tecnológicos.

No RP, a reflexão a respeito da formação para a cidadania crítica e o papel que o aprendizado de inglês pode desempenhar nesse processo é um ponto central considerado na construção dos projetos a serem desenvolvidos nas escolas. Sobre ações futuras, há dois minicursos a serem ofertados: um sobre o tema bullying e o outro sobre o ensino de inglês para alunos com necessidades especiais. A escolha por esses temas surgiu do contato com as escolas, no cotidiano das ações realizadas no RP; e nos encontros dos dois núcleos de inglês na UFS.

São muitos os desafios a serem enfrentados, incluindo as implicações negativas que cortes nas verbas destinadas à educação já imprimem ao programa. Um exemplo disso são as proibições relativas à inclusão de novos residentes em substituição aos que estão finalizando vínculo com o programa, como é o caso de alguns formandos e de outros residentes que receberam propostas de emprego. Apesar do clima de incertezas referente ao futuro do programa, nossos esforços são no sentido da manutenção do comprometimento com o desenvolvimento do programa, o que vem trazendo resultados positivos para a formação de todos os envolvidos: discentes, docentes e discentes da rede pública e nós, coordenadoras professoras do ensino superior.

\section{CONSIDERAÇÕES FINAIS}

As propostas governamentais para a formação de professores, especialmente aquelas que não são construídas coletivamente, tendem a ser homogeneizantes. $O$ principal desafio no momento de implementação de programas como Pibid e RP é 
ressignificá-los, considerando-se as características locais de um determinado contexto sócio-histórico-cultural (BRUNER, 1990; MENEZES DE SOUZA, 2011a; 2011b).

Tanto o Pibid quanto o RP são programas que podem contribuir para a formação inicial de alguns alunos das licenciaturas complementando os conteúdos previstos na grade curricular dos cursos. Pelas restrições impostas pelo edital da CAPES para a participação nos programas - quantidade de bolsas disponíveis (192 nos casos do Pibid e RP de inglês da UFS) inferior à quantidade de alunos (aproximadamente 500 alunos), disponibilidade de horas para desenvolver as atividades do projeto que inclui visita às escolas - a maioria dos alunos não tem a oportunidade de vivenciar as experiências na educação básica durante todo o curso, já que na grade curricular está previsto o início desse tipo de atividade no $5^{\circ}$ semestre da licenciatura. Nesse sentido, é importante que sejam amplamente divulgados os bons resultados na formação inicial dos licenciandos que participaram de tais programas de forma que possa haver uma sensibilização relativa a propostas de ampliação e democratização de tais programas.

Atuar nesses programas como coordenadora institucional e coordenadoras de área do Pibid e do RP tem sido um grande desafio no sentido de buscar refletir constantemente sobre nossos papéis como formadoras de professores, o que a construção desse artigo buscou evidenciar. A escrita conjunta e o diálogo certamente funcionou como mais uma chance de refletirmos sobre a nossa formação e nosso papel de professoras formadoras, levando-nos a uma releitura das nossas vivências e experiências.

\section{REFERÊNCIAS}

BRASIL. CAPES. Programa Institucional de Bolsa de Iniciação à Docência. Edital n.061/2013. Disponível em: https://www.capes.gov.br/images/stories/download/editais/ Edital_061_2013_Pibid.pdf. Acesso em: 27 fev. 2019.

BRASIL. Conselho Nacional de Educação. Resolução 02/15. Institui as Diretrizes Curriculares Nacionais para a Formação Inicial e Continuada dos Profissionais do Magistério. Disponível em: http://portal.mec.gov.br/docman/agosto-2017-pdf/70431res-cne-cp-002-03072015-pdf/file. Acesso em: 27 fev. 2019.

BRASIL. Edital CAPES 06/2018. Chamada Pública para apresentação de propostas no âmbito do Programa de Residência Pedagógica. Disponível em: http://capes.gov.br/ images/stories/download/editais/27032018-Edital-6-Residencia-Pedagogica-AlteracaoII.pdf. Acesso em: 27 fev. 2019. 
BRASIL. Edital CAPES n. 07/2018. Chamada Pública para apresentação de propostas no âmbito do Programa Institucional de Bolsa de Iniciação à Docência. Disponível em: https://www.capes.gov.br/images/stories/download/editais/01032018-Edital-7-2018PIBID.pdf. Acesso em: 27 fev. 2019.

BRASIL. Lei de Diretrizes e Bases da Educação Nacional (LDB) n ${ }^{\circ} 9.394$ de 20 de dezembro de 1996. Estabelece as diretrizes e bases da educação nacional. Disponível em: http://www.planalto.gov.br/ccivil_03/leis/19394.htm Acesso em: 11 fev. 2018.

BRUNER, J. Acts of meaning. Cambridge, Mass.: Harvard University Press, 1990.

CANAGARAJAH, A.S. Reclaiming the local in language policy and practice. Journal of Language, Identity \& Education, v. 1, n. 4, p. 243-259, 2002.

DARDOT, P.; LAVAL, C. The new way of the world: on neoliberal society. Trans. Gregory Elliott. London/New York: Verso, 2013.

JESUS, D. M. de; LIMA, T. B. Para além do discurso do fracasso: os sentidos da aprendizagem de alunos de língua inglesa de uma escola pública. In: JESUS, D. M. de; CARBONIERE, D. (Orgs.). Práticas de multiletramentos e letramento crítico: outros sentidos para a sala de aula de línguas. Campinas, SP: Pontes Editores, 2016. p. 81-98.

JORDÃO, C. M. Abordagem comunicativa, pedagogia crítica e letramento crítico farinhas do mesmo saco? In: ROCHA, C. H.; FRANCO MACIEL, R. (Orgs.). Língua Estrangeira e Formação Cidadã: por entre discursos e práticas. Coleção: Novas Perspectivas em Linguística Aplicada. Vol. 33. Campinas, SP: Pontes Editores, 2013. p. 69-90.

JORDÃO, C. M. No tabuleiro da professora tem...letramento crítico?.... In: JESUS, D. M. de; CARBONIERE, D. (Orgs.). Práticas de multiletramentos e letramento crítico: outros sentidos para a sala de aula de línguas. Campinas, SP: Pontes Editores, 2016. p. 41-53.

JUCÁ, L. Ensinando inglês na escola regular: a escolha dos caminhos a seguir depende de onde se quer chegar. In: JESUS, D. M. de; CARBONIERE, D. (Orgs.). Práticas de multiletramentos e letramento crítico: outros sentidos para a sala de aula de línguas. Campinas, SP: Pontes Editores, 2016. p. 99-120.

KUMARAVADIVELU, B. The Decolonial Option in English Teaching: Can the subaltern act. TESOL QUARTERLY, V.0, n.0, 2014. p.1-20.

MENEZES DE SOUZA, L. M. T. O Professor de Inglês e os Letramentos no século XXI: métodos ou ética? In: JORDÃO, C. M.; MARTINEZ, J. Z.; HALU, R. C. (Orgs.). Formação desformatada - práticas com professores de língua inglesa. Coleção: Novas Perspectivas em Linguística Aplicada Vol. 15. Campinas, SP: Pontes Editores, 2011a., p. 279-303. 
MENEZES DE SOUZA, L. M. T. Para uma redefinição de letramento crítico: conflito e produção de significação. In: MACIEL, R.F.; ARAÚJO, V.A. (Orgs.). Formação de Professores de Línguas: ampliando perspectivas. Jundiaí: Paco Editorial, 2011b, p. 128-140.

MONTE MÓR, W. Sobre homogeneidade e heterogeneidade no ensino de línguas e as influências dos conceitos 'estado-nação' e 'globalização'. In: TAVARES, R.; BRYDON, D. Letramentos transnacionais: mobilizando conhecimento entre Brasil/Canadá. Maceió: Edufal, 2013.

NASCIMENTO, A. K. de O. Formação Inicial de Professores de Inglês e Letramentos Digitais: uma análise por meio do Pibid. Tese de Doutorado. 2017. 240f. Tese (Doutorado em Letras) - Programa de Pós-Graduação em Estudos Linguísticos e Literários em Inglês da Universidade de São Paulo, São Paulo, 2017.

NASCIMENTO, A. K. Neoliberalismo e Língua Inglesa: um estudo de caso por meio do Pibid. Ilha do Desterro, Florianópolis, v. 71, n. 3, p. 39-58, dez. 2018. Disponível em $\quad$ http://www.scielo.br/scielo.php?script=sci_arttext\&pid=S217580262018000300039\& lng=pt\&nrm=iso. Acesso em: 29 jan. 2019.

PATRICK, F. Neoliberalism, the Knowledge Economy, and the Learner: Challenging the Inevitability of the Commodified Self as an Outcome of Education, ISRN Education, p. 1-8, 2013. doi:10.1155/2013/108705.

STIEGLER, B. States of Shock: Stupidity and Knowledge in the 21st Century. Trans. Daniel Ross. Cambridge, UK: Polity Press, 2015.

SUÁREZ-OROZCO, M.; QIN-HILIARD, D. B. Globalization Culture and Education in the New Millennium. In: SUÁREZ-OROZCO, M.M. (Org.). Learning in the Global Era: International Perspectives on Globalization and Education. Califórnia: University of California Press, 2007.

UNIVERSIDADE FEDERAL DE SERGIPE (UFS). Subprojeto de Inglês do Pibid 2018. Arquivo pessoal.

UNIVERSIDADE FEDERAL DE SERGIPE (UFS). Edital N 22/2018/PROGRAD. Processo seletivo de licenciandos (as) para o Programa Institucional de Bolsa de Iniciação à Docência (Pibid). São Cristóvão, 14 de junho de 2018.

UNIVERSIDADE FEDERAL DE SERGIPE (UFS). Edital N ${ }^{\circ}$ 24/2018/PROGRAD. Processo seletivo para supervisor pedagógico do Programa Institucional de Bolsa de Iniciação à Docência (Pibid). São Cristóvão, 21 de junho de 2018.

UNIVERSIDADE FEDERAL DE SERGIPE (UFS). Edital No10/2018/PROGRAD. Chamada Pública para aos Departamentos que ofertam cursos de Licenciatura para participação no Programa de Residência Pedagógica da UFS. São Cristóvão, 15 de março de 2018. 